\title{
Medication Adherence Mediates the Association between Type D Personality and High HbA1c Level in Chinese Patients with Type 2 Diabetes Mellitus: A Six-Month Follow-Up Study
}

\author{
Xuemei Li, ${ }^{1,2}$ Min Gao, ${ }^{1}$ Shengfa Zhang, ${ }^{1}$ Huiwen Xu, ${ }^{3}$ Huixuan Zhou, ${ }^{1}$ Xiaohua Wang, \\ Zhiyong Qu, ${ }^{1}$ Jing Guo, ${ }^{4}$ Weijun Zhang, ${ }^{1}$ and Donghua Tian ${ }^{1}$ \\ ${ }^{1}$ School of Social Development and Public Policy, China Institute of Health, Beijing Normal University, Beijing 100875, China \\ ${ }^{2}$ Clinics of Cadre, Department of Outpatient, General Hospital of the People's Liberation Army (301 Hospital), Beijing 100853, China \\ ${ }^{3}$ Department of Public Health Sciences, University of Rochester School of Medicine \& Dentistry, Rochester, NY 14642, USA \\ ${ }^{4}$ Department of Sociology, Huazhong University of Science and Technology, Wuhan, Hubei 430074, China
}

Correspondence should be addressed to Weijun Zhang; zwj@bnu.edu.cn and Donghua Tian; tian65216@hotmail.com

Received 16 September 2016; Revised 23 November 2016; Accepted 7 December 2016; Published 9 February 2017

Academic Editor: Suat Simsek

Copyright (C) 2017 Xuemei Li et al. This is an open access article distributed under the Creative Commons Attribution License, which permits unrestricted use, distribution, and reproduction in any medium, provided the original work is properly cited.

\begin{abstract}
Aims. To examine the association between Type D personality and HbAlc level and to explore the mediating role of medication adherence between them in patients with type 2 diabetes mellitus (T2DM). Methods. 330 patients went on to complete a selfreport measure of medication adherence and the HbAlc tests. Chi-square test, $T$ test, Ordinary Least Square Regression (OLS), and Recentered Influence Function Regression (RIF) were employed. Results. Patients with Type D personality had significantly higher HbAlc value $(P<0.01)$. When Type $\mathrm{D}$ personality was operationalized as a categorical variable, SI was associated with HbAlc $(P<0.01)$. When NA, SI, and their interaction term were entered into regression, all of them were no longer associated with HbAlc level $(P>0.1)$. On the other hand, when Type D personality was operationalized as a continuous variable, only SI trait was associated with $\mathrm{HbAlc}$ level $(P<0.01)$. When NA, SI, and NA $\times$ SI term together were entered into regression, only SI was not related to HbAlc level. Furthermore, medication adherence had a significant mediation effect between Type D personality and $\mathrm{HbAlc}$, accounting for $54.43 \%$ of the total effect. Conclusion. Type D personality was associated with HbAlc in direct and indirect ways, and medication adherence acted as a mediator role.
\end{abstract}

\section{Introduction}

Adherence has been defined by WHO as "the extent to which a person's behavior-taking medications, following a diet, and/or executing lifestyle changes, corresponds with agreed recommendations from a health care provider" [1]. Adequate adherence enhances treatment safety and treatment effectiveness and further leads to reduced mortality, morbidity, and considerable direct and indirect costs to healthcare system $[2,3]$. In addition, accumulating evidence presented that Type D personality is significantly associated with medication adherence in patients with chronic disease $[4,5]$ and has a deleterious influence on the patient's self-behavior
[6]. Patients with Type D personality may be nonadherent because of the concerns about negative side-effects of medication and the inability to talk about these concerns [7], or due to fewer health-enhancing behaviors, such as eating sensibly and getting a regular medical examination [6]. Additionally, people with high SI might adhere to treatment less because they tend to use more avoidant and passive coping strategies (e.g., denial) when dealing with (medical) problems [8]. Previous studies revealed that poor self-management such as medication adherence can lead to life-threating complications including microvascular or macrovascular disease for the patients with T2DM [9], or with chronic heart failure [10], and/or with peripheral arterial disease [11]. 
Diabetes is a main contributor for death, disability, and rising medical expenses in both developed countries and developing countries. The majority of diabetes-related complications may be the result of higher blood glucose level, especially the elevated blood sugar over a prolonged period of time [12]. Glycated haemoglobin (HbAlc), which reflects the average blood glucose level over $8-12$ weeks and provides a useful longer-term gauge of blood glucose control [13], has been used as an objective marker of average glycaemic control for a long time [14]. Also, HbAlc has been endorsed as a diagnostic test for diabetes by the World Health Organization (WHO), the International Diabetes Federation (IDF), and the American Diabetes Association (ADA) [15-18].

Recently, a six-month follow-up study, conducted by our research team, showed that Type D personality predicted poor medication adherence in Chinese patients with Type 2 diabetes mellitus (T2DM) $(P<0.001)$ [19]. A rapidly growing number of studies have also suggested that poor medication adherence will lead to higher blood glucose level and increased risks of complications. For example, a more recent study, conducted in Maastricht, indicated that people with Type D personality had significantly higher levels of HbAlc and fasting glucose $(P=0.008)$ [20]. Therefore, this study aimed to explore whether there is a direct association between Type D personality and higher HbAlc level, or whether medication adherence acted as a mediating role, or whether both the direct and the indirect association coexist between Type D personality and HbAlc in Chinese population with T2DM, after controlling for demographic, clinical, and behavioral characteristics.

\section{Materials and Methods}

2.1. Participants. The sample procedures have been introduced in our previously published articles [19, 21]. The baseline survey was conducted from March 1 to May 31, 2012; patients completed measures of Type D personality and provided demographic information, clinical outcomes, and so on. Six months later, patients were contacted again to complete a self-report measure of medication adherence and HbAlc test. Eventually, 330 participants completed the follow-up investigation and accepted HbAlc test after receiving informed consent, at the six-month follow-up (Time 2, T2) [19]. No significant differences were found between the respondents and nonrespondents in gender, HbAlc level at baseline, and Type D personality, except for the age [19].

\subsection{Measurements. Demographic Information and Clinical} Characteristics. The variable information at baseline and six months later in this study has been described in our previous articles $[19,22]$. Specifically, the demographic and socioeconomic factors, life behavior factors, and clinical characteristics information were collected at baseline. Meanwhile, medication adherence information was also gathered at six months later.

Type D Personality. Type D personality was assessed by using the Chinese version of DS14 scale [23], consisting of Negative Affectivity (NA) and Social Inhibition (SI). The cut-off of $\geq 10$ on both subscales indicating Type D personality. In this study, Cronbach's $\alpha$ were 0.89 and 0.93 for the NA and SI [19], respectively.

HbAlc Value. In this study, HbAlc, which was obtained at baseline and six months later, is used as the marker of average glycaemic control. It has been reported that there is a strong positive correlation between HbAlc and blood glucose [17, 18]. The results of Diabetes Control and Complications Trial (DCCT) showed that when HbAlc increases $1 \%$, the average blood glucose increases by $1.95 \mathrm{mmoL} / \mathrm{L}$ [24].

Medication Adherence. The Chinese version of the Medication Adherence Scale (MMAS-8-CN) was adopted to evaluate medication adherence [25]. In this study, Cronbach's $\alpha$ based on standardized items is 0.84 [19].

2.3. Statistical Analyses. In order to explore the relationship between Type D personality and HbAlc value in patients with T2DM, the following analytic strategies were employed. Firstly, since the dependent variable HbAlc was a continuous variable, Ordinary Least Square (OLS) regression was employed to explore the relation of the Type D personality and $\mathrm{HbAlc}$ value. Secondly, the method of Recentered Influence Function Regression (RIF) was employed to estimate directly the impact of the explanatory variables on the distributional statistic of interest. RIF showed how to formally decompose changes in the distribution of the dependent variable ( $\mathrm{HbAlc})$ into the contribution of independent factors (Type D personality). The dependent variable (HbAlc) was divided into several parts by quantile: 25 th, 50 th, 75 th, in order to explore how Type D personality influence HbAlc value [26]. Thirdly, Type D personality was regarded as a classified variable; that is, it was recoded into a binary variable based on whether both NA and SI scored above the recommended cut-off $(>10)$; then the interaction term of NA $\times$ SI was entered to test whether it could explain additional variance. Fourthly, NA and SI were treated as continuous variables; in addition, the multiplicative NA $\times$ SI term was also entered. Finally, Product of Coefficients Approach was employed to identify whether medication adherence is an intervening variable between Type D personality and HbAlc [27].

2.4. Ethics Statement. This study was approved by the Ethics Committee of School of Social Development and Public Policy at Beijing Normal University and the Ethics Committee of the First Affiliated Hospital of the General Hospital of PLA. All patients provided written informed consent, and all personal information was kept confidential and reporting was made anonymous.

2.5. Availability of Supporting Data. The database set was available for all authors of the study and will be available for other noncommercial researchers on request.

\section{Results}

3.1. Subjects Characteristics. Subjects' characteristics have been described in our previous article [19]. Among 330 participants, the average age was 57.23 years old, and 158 (47.88\%) 
TABLE 1: Sample characteristics.

\begin{tabular}{|c|c|c|c|c|}
\hline & $\begin{array}{l}\text { Total sample } \\
(n=330)\end{array}$ & $\begin{array}{c}\text { Type D } \\
\text { personality } \\
(n=92)\end{array}$ & $\begin{array}{c}\text { Non-Type D } \\
\text { personality } \\
(n=238)\end{array}$ & $P$ value \\
\hline $\begin{array}{l}\text { Personal income last } \\
\text { year }\end{array}$ & $5.02 \pm 9.20$ & $4.28 \pm 8.58$ & $5.30 \pm 9.44$ & $t=0.901, P=0.368$ \\
\hline $\begin{array}{l}\text { Reimbursement ratio } \\
\text { of treatment costs }\end{array}$ & $77.25 \pm 24.43$ & $72.03 \pm 31.48$ & $79.27 \pm 20.80$ & $t=2.430, P=0.016$ \\
\hline
\end{tabular}

TABLE 2: The comparison of the clinical outcomes between the patients with or without Type D personality.

\begin{tabular}{lcccc}
\hline & Total $(n=330)$ & Type D personality $(n=92)$ & Non-Type D personality $(n=238)$ & $P$ value \\
\hline Duration & $7.872 \pm 5.477$ & $9.228 \pm 6.722$ & $7.349 \pm 4.827$ & $t=-2.82, P=0.005$ \\
The number of complications & $2.176 \pm 1.785$ & $2.467 \pm 2.019$ & $2.063 \pm 1.676$ & $t=-1.85, P=0.065$ \\
Cost of treating diabetes & $0.842 \pm 1.788$ & $1.092 \pm 3.244$ & $0.746 \pm 0.592$ & $t=-1.58, P=0.114$ \\
BMI & $25.010 \pm 3.154$ & $25.668 \pm 3.054$ & $24.755 \pm 3.162$ & $t=-2.37, P=0.018$ \\
HbAlc at baseline & $7.312 \pm 2.004$ & $7.214 \pm 1.846$ & $7.350 \pm 2.064$ & $t=0.55, P=0.581$ \\
HbAlc at T2 & $7.017 \pm 1.003$ & $7.514 \pm 1.376$ & $6.824 \pm 0.733$ & $t=-5.88, P<0.001$ \\
Medication adherence & $5.44 \pm 2.445$ & $4.323 \pm 2.505$ & $5.8981 \pm 2.258$ & $t=2.257, P<0.001$ \\
\hline
\end{tabular}

were males. In addition, there was a significant difference in the reimbursement ratio of treatment costs between T2DM patients with or without Type D personality $(P=0.016)$ (Table 1). However, there was no significant difference in personal income last year between T2DM patients with or without Type D personality $(P=0.368)$ (Table 1$)$.

3.2. Clinical Characteristics. As shown in Table 2, at baseline, patients with Type D personality presented longer duration $(t=-2.82, P=0.005)$, more complications $(t=-1.85$, $P=0.065)$, and higher BMI scores $(t=-2.37, P=0.018)$, compared with that without Type $\mathrm{D}$ personality. However, HbAlc level $(t=0.55, P=0.581)$ and cost of treating diabetes $(t=-1.58, P=0.114)$ were not significantly different between the T2DM patients with or without Type D personality. At the followup, the average of HbA1c level was 7.02 (SD = 1.003), with the range of 5.2-14.2. Patients with Type D personality presented higher HbAlc value $(t=-5.88$, $P<0.001)$ and lower medication adherence $(t=2.257$, $P<0.001)$, compared with their counterparts.

3.3. Type D Personality Predicted Higher HbAlc Level at T2. As shown in Table 3, the first step of Ordinary Least Square Regression (OLS) included age, gender, and education variables, which did not account for a significant amount of HbAlc at T2, and the total adjust- $R^{2}$ was 0.092 . The clinical factors and behavior factors explained an additional $74.5 \%$ of the variance in step 2 . There is one point which needs attention; that is, Type $\mathrm{D}$ personality had a significant influence on higher HbAlc level $(\beta=0.357, P<0.01)$, which explained the additional $0.7 \%$ of the variance, in the final step.

As shown in the fourth to sixth columns of Table 3, Recentered Influence Function Regression (RIF) further confirmed the effect of Type $\mathrm{D}$ personality on HbAlc level at
T2. Type D personality had a significant association with high (75th) percentile of HbAlc value $(\beta=0.646, P<0.01)$, but it was not related to low (25th) percentile and median (50th) percentile of HbAlc value. Concurrently, the covariates such as age $(\beta=0.020, P<0.05)$ and marital status $(\beta=$ $0.252, P<0.01)$ were also associated with high percentile of HbAlc significantly. Meanwhile, clinical characteristics also influenced HbAlc significantly; the subjects with long duration $(\beta=-0.077, P<0.01)$ tended to have lower HbAlc level; however, those with more complications $(\beta=$ $0.161, P<0.01)$ and higher medical cost $(\beta=0.069, P<$ 0.05 ) tended to have higher HbAlc level among patients with medium or above HbAlc level. Interestingly, the subjects with diabetes family history were inclined to have lower HbAlc level $(\beta=0.506, P<0.01)$. In terms of behavior factors, sleep time per day had a significantly positive association with HbAlc level among patients with high HbAlc $(\beta=0.239$, $P<0.01)$. Among the patients with low HbAlc percentile, however, exercise time per week $(\beta=0.096, P<0.01)$ and drinking alcohol $(\beta=-0.310, P<0.05)$ were significantly associated to HbAlc level.

As shown in Table 4, Type D personality was operationalized as a categorical variable [28], that is, NA and SI, which were regarded as the categorical variables, were entered into the regression model (step 1). There was a different influence on HbA1c level at T2; SI was significantly associated with HbAlc $(\beta=0.395, P<0.01)$. However, when NA, SI, and their interaction term $(\mathrm{NA} \times \mathrm{SI}$ term) were entered into multiple regression model, all of them were no longer significantly associated with $\mathrm{HbAlc}$ level $(P>0.1)$, and total adjust- $R^{2}$ remained unchanged (step 2$)$.

To further explore the associations between NA/SI trait and HbA1c level at T2, NA and SI, which were regarded as continuous variables, were entered into multiple regression 


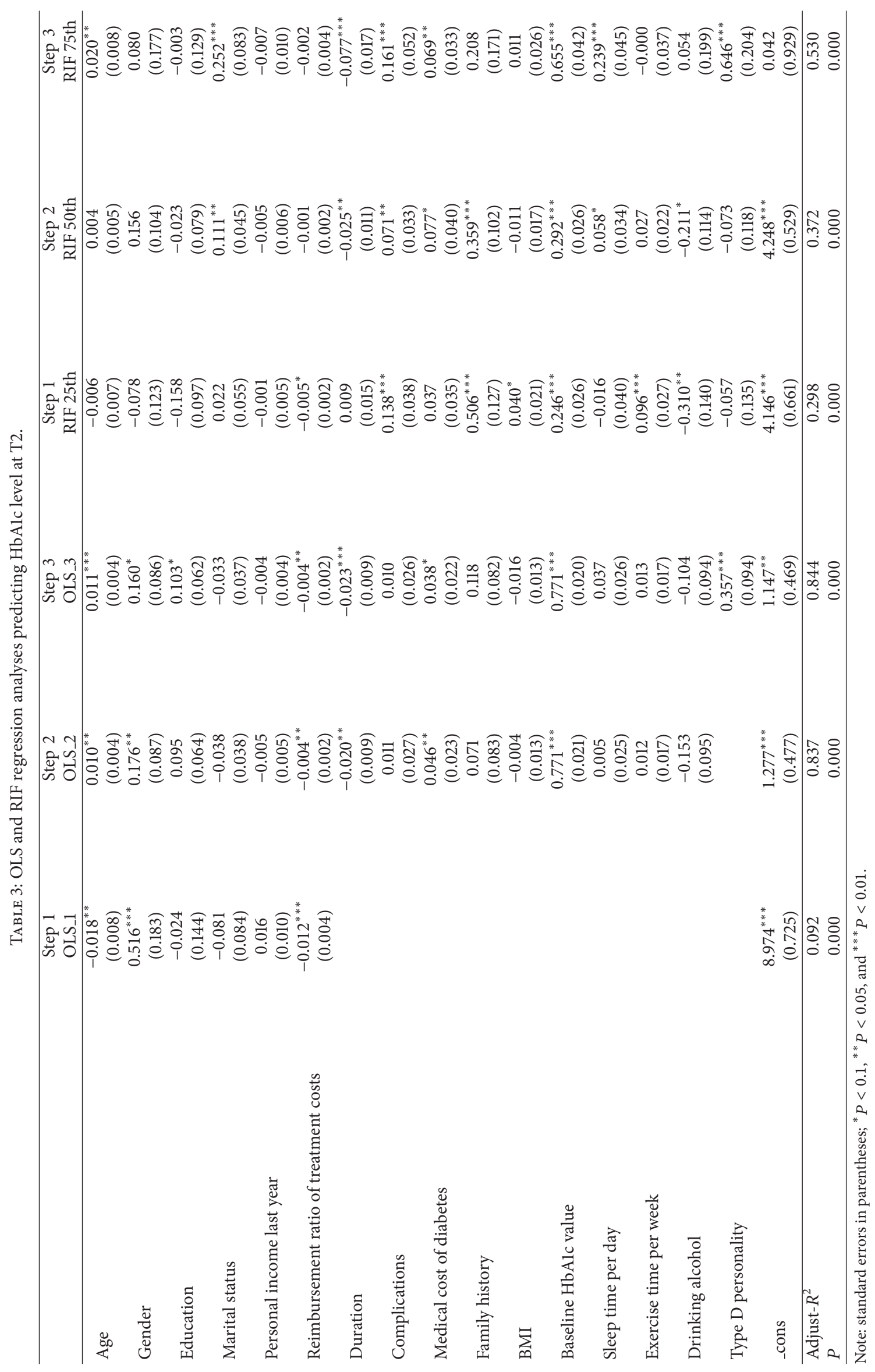




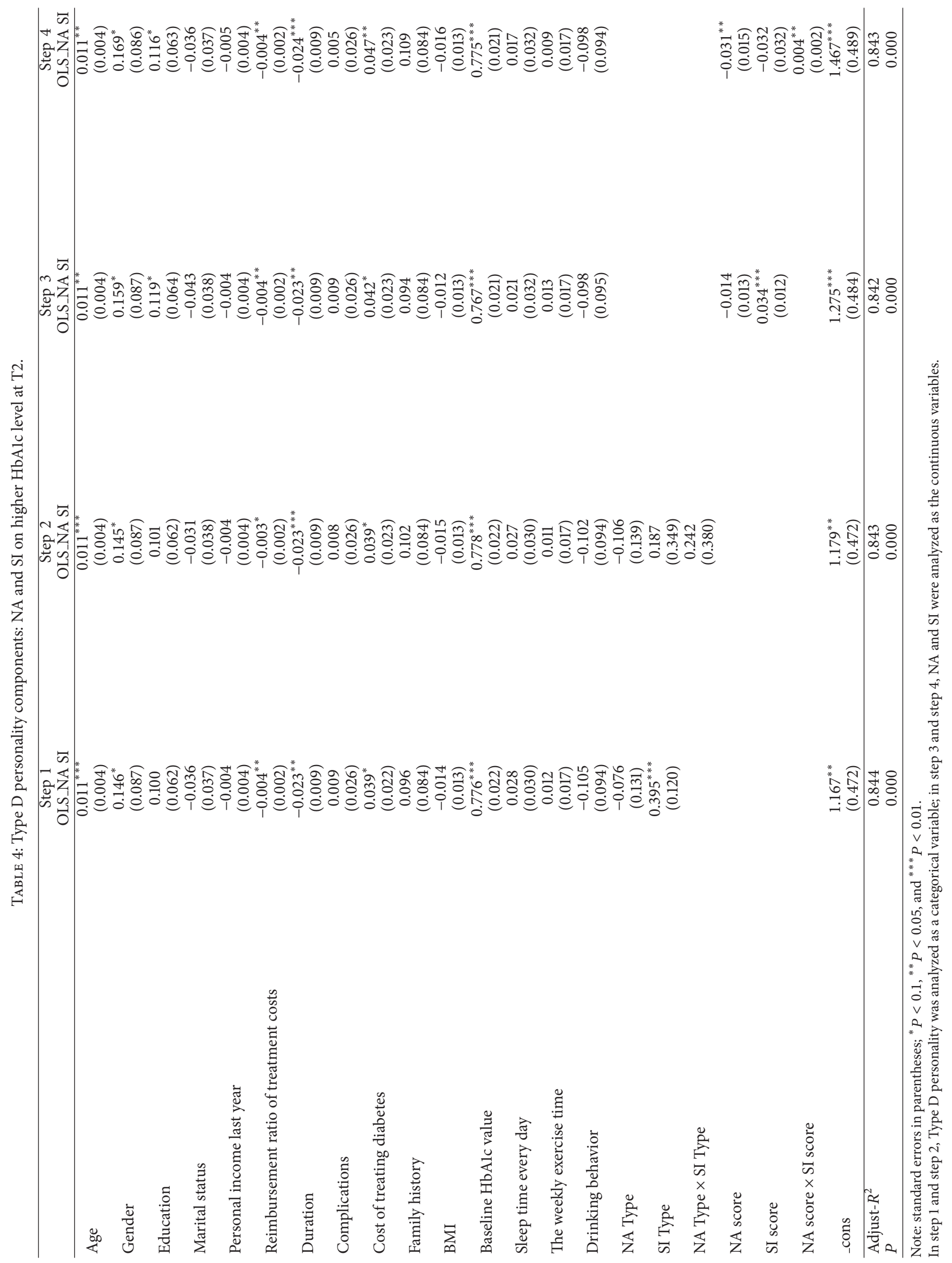


TABLE 5: Mediation effect between Type D personality and HbAlc.

\begin{tabular}{|c|c|c|c|c|}
\hline & $\begin{array}{c}\text { A path } \\
\text { Direct effects of Type } \\
\text { D personality on } \\
\text { medication adherence }\end{array}$ & $\begin{array}{c}\text { B path } \\
\text { Direct effects of } \\
\text { medication adherence } \\
\text { on HbAlc }\end{array}$ & $\begin{array}{c}\text { C path } \\
\text { Direct effects of Type } \\
\text { D personality on } \\
\text { HbAlc }\end{array}$ & $\begin{array}{c}C^{\prime} \text { path } \\
\text { Coeffect of Type D } \\
\text { personality and } \\
\text { medication } \\
\text { compliance }\end{array}$ \\
\hline \multirow{2}{*}{$\begin{array}{l}\text { Type D } \\
\text { personality }\end{array}$} & $-1.903^{* * *}$ & & $0.357^{* * *}$ & $0.247^{* *}$ \\
\hline & $(0.235)$ & & $(0.094)$ & $(0.102)$ \\
\hline \multirow{2}{*}{$\begin{array}{l}\text { Medication } \\
\text { adherence }\end{array}$} & & $-0.080^{* * *}$ & & $-0.058^{* *}$ \\
\hline & & $(0.021)$ & & $(0.022)$ \\
\hline \multirow{2}{*}{ _cons } & $10.704^{* * *}$ & $2.082^{* * *}$ & $1.147^{* *}$ & $1.766^{* * *}$ \\
\hline & $(1.174)$ & $(0.510)$ & $(0.469)$ & $(0.523)$ \\
\hline Adjust- $R^{2}$ & 0.519 & 0.844 & 0.844 & 0.847 \\
\hline \multirow[t]{2}{*}{$P$} & 0.000 & 0.000 & 0.000 & 0.000 \\
\hline & Mediation effect & $42.64 \%$ & $\begin{array}{l}\text { Mediating effect of } \\
\text { total effect }\end{array}$ & $54.43 \%$ \\
\hline
\end{tabular}

Note: (1) standard errors in parentheses; ${ }^{*} P<0.1,{ }^{* *} P<0.05$, and ${ }^{* * *} P<0.01$.

(2) Mediation effect calculation: $E=\beta(\mathrm{A}$ path $) * \beta(\mathrm{B}$ path $) / \beta(\mathrm{C}$ path $)=(-1.903) *(-0.080) / 0.357=42.64 \%$.

(3) Mediating effect of total effect calculation: $P=E($ Mediation Effect $) /(E($ Mediation Effect $)+\beta(C$ path $))=42.64 \% /(42.64 \%+37.7 \%)=54.43 \%$.

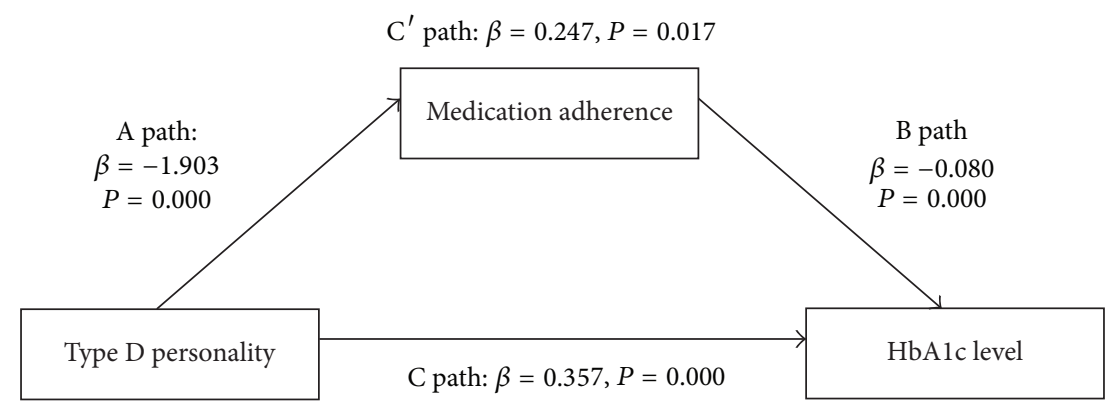

Figure 1: Medication adherence as a mediator between Type D personality and Type D personality after discharge. Note: A path: the independent variable (Type D personality) significantly influences the dependent variable (HbAlc level at T2) in the absence of the mediator (medication adherence). B path: the mediator (medication adherence) has a significant unique effect on the dependent variable (HbAlc level at T2) and also means that the direct effect of medication adherence on the dependent variable (HbAlc level at T2). C path: the independent variable (Type D personality) significantly influences the dependent variable (HbAlc level at T2). $\mathrm{C}^{\prime}$ path: the independent variable (Type D personality) significantly influences the dependent variable (HbAlc level at T2) on the addition of the mediator (medication adherence).

model (step 3). The results showed that SI trait has a significantly positive correlation with $\mathrm{HbA1c}$ level at T2 $(\beta=$ $0.034, P<0.01)$, but NA trait was not associated with HbAlc level at T2 significantly $(P>0.1)$. One thing to be noted, when NA, SI, and NA $\times$ SI term together were entered into the Multiple Regression (step 4$)$, NA $(\beta=-0.031, P<0.05)$ and their interaction term $(\beta=0.004, P<0.05)$ were related to HbAlc level at T2.

3.4. Medication Adherence Acted as a Mediator Variable. As shown in Table 5 and Figure 1, Type D personality had a direct and indirect influence on HbAlc level at T2 in patients with T2DM. Based on the results above, a hypothesis was proposed that medication adherence might be the mediator variable between Type D personality and HbA1c level at T2. Therefore,
Product of Coefficients Approach was employed to estimate indirect effects of Type D personality through medication adherence in a simple mediation model (Figure 1): (1) A path represents the direct effect of Type D personality on medication adherence $(\beta=-1.903, P<0.01)$; (2) $\mathrm{B}$ path represents the direct effect of medication adherence on HbAlc level at T2 $(\beta=-0.080, P<0.01)$; (3) $\mathrm{C}$ path represents the direct effect of Type D personality on HbAlc level at T2 $(\beta=0.357, P<0.01)$; (4) $\mathrm{C}^{\prime}$ path presents the coeffects of Type $\mathrm{D}$ personality and medication compliance on HbAlc level at T2 $(\beta=0.247, P<0.05)$. The results confirmed the hypothesized mediating role for medication adherence between Type D personality and HbAlc level at T2. Based on the results of Product of Coefficients Approach, medication adherence had a significant mediation effect 
between Type D personality and HbAlc level at T2, and the coefficient is $42.64 \%$, and accounting for $54.43 \%$ of the total effect (Table 5).

\section{Discussion}

To the best of our knowledge, this may be the first study to explore the potentially important mediational pathway between Type $\mathrm{D}$ personality and $\mathrm{HbAlc}$ level in patients with T2DM.

In this study, we have identified that Type $\mathrm{D}$ personality is an independent predictor of HbAlc level at T2, after controlling demographic, clinical and behavior factors $(\beta=0.357$, $P<0.01$ ), especially for patients with high (75th) percentile of HbAlc value. In addition, the constituent components of Type D personality (NA and SI) had different influence on HbAlc. As a categorical or continuous variable, SI was significantly associated with $\mathrm{HbAlc}$, whereas NA was not. But when NA, SI, and their interaction term $(\mathrm{NA} \times \mathrm{SI}$ term) together were entered into the regression as categorical variables, all of them were no longer significantly associated with HbAlc $(P>0.1)$. However, when NA, SI, and their interaction term $(\mathrm{NA} \times \mathrm{SI}$ term) together were entered into the regression as continuous variables, NA and the interaction term $(\mathrm{NA} \times \mathrm{SI}$ term) had significant associations with $\mathrm{HbAlc}$ level at T2. In addition, the study also suggested that medication adherence was an important mediational pathway between Type D personality and HbAlc level at T2 in patients with T2DM, and the coefficient is $42.64 \%$.

The findings showed that Type D personality was significantly associated with higher HbAlc level at T2 in patients with T2DM, which were similar to the high prevalence rates of Type D personality in other patient groups such as those suffering from hypertension, myocardial infarction, and heart failure $[4,29]$. Personality is formed by family environment, school education, personal physical condition, and social environment and other factors. Several studies indicated that Type D personality predicted the lower objective assessed adherence in patients with obstructive sleep apnea syndrome [30] and was strongly associated with lower adherence to oral appliance therapy in patients with sleepdisordered breathing [31] and displayed inadequate selfmanagement in patients with heart failure [32]. Another study showed that people with Type D personality are more inclined to be worried, anxious, pessimistic, and angry and inhibit self-expression in social interactions in order to avoid disapproval or rejection by others [33]. This study also showed that T2DM patients with Type D personality have poorer medication adherence and have more difficulty in controlling HbAlc level, compared with that without Type D personality. Furthermore, Type D personality has a strong influence on high percentile rank of HbA1c level at T2, which means, for patients with higher HbAlc, the effect of Type D personality is becoming more obvious; meanwhile, Type D personality also has a weak influence on low percentile rank of HbAlc.

To explore the mediating effect of medication adherence between Type D personality and HbAlc level was another important contribution of this study. It is well known that the issues regarding the relationship between Type D personality and health outcomes remained unclear. Although, recent studies found that Type D personality may be related to immune activation [34], hyperactivity of the hypothalamicpituitary-adrenal axis [35], greater cardiovascular reactivity to stress [36], engagement in fewer health-related behaviors [6], depression [37], and suboptimal consultation behaviors [38]. Furthermore, there was also some evidence for a number of potential psychobiological mechanisms that may operate between Type D personality and poor health outcomes [35, 36, 39] and increasing evidence for behavioral mechanisms including self-management behaviors in cardiac patients $[6,40]$. It is easy to understand that medication adherence, as a typical self-management behavior, should have a significant effect on $\mathrm{HbAlc}$ level. Once patients do not adhere to medication, the blood glucose level of patients will inevitably be influenced by the poor medication adherence. Previous studies have identified that high level of HbAlc will increase risks of having relevant complications [28, 41]. Therefore, after controlling for demographic, clinical, and behavioral characteristics, the questions on whether there is a direct association between Type $\mathrm{D}$ personality and HbAlc level, or whether medication adherence acts as a mediating role, or whether both the direct and the indirect association coexist between the Type D personality and HbAlc level were especially important and should be further resolved.

In this study, the results of Product of Coefficients Approach (PCA) analysis showed that medication adherence played a significant mediating effect between Type D personality and HbAlc level, which means Type D personality not only had a direct but also had an indirect influence on HbAlc level through medication adherence. In other words, as a negative personality, Type D personality may directly influence the HbAlc level through affecting patients' enthusiasm or activating a certain inherent mechanism in vivo, which should be further explored by conducting interdisciplinary research in the future; concurrently, it also has an adversely influence on the HbA1c level through lowering patients' medication adherence. Naturally, in this way, diabetic condition should certainly become more difficult to be controlled, and HbAlc level would remain obstinately high.

Traditionally, Type D personality was always employed as a categorical variable based on the scores of NA and SI above the median split [42]; however, the issue, which should not be ignored, considering Type D personality as a dichotomized variable may lead to a wrong outcome [43]. Therefore, the question on what Type D personality should be regarded as a continuous variable or a categorical variable still remains unclear. A recent study also suggested that Type $\mathrm{D}$ personality may be better considered as a dimensional construct than a categorical construct, because the whole range of data can more objectively reveal the facts and details [44]. However, a 5-year follow-up of 541 patients with $\mathrm{CAD}$ showed that continuous $(\mathrm{NA} \times \mathrm{SI}$ interaction) and dichotomized measures of Type $\mathrm{D}$ were associated with cardiovascular events in patients with CAD, and both measurement approaches showed similar results [45]. There are also some concerns regarding the use of potentially artificial cut points to construct typology which may result in 
the likelihood of spurious results [46]. It has also been argued that it would be better to look at the interaction of continuous NA and SI scores to test whether it is indeed the synergistic effect of NA and SI [47].

In this study, when Type D personality was analyzed as a categorical variable, SI has an adverse effect on HbAlc level. It showed that negative affectivity (NA) and social inhibition (SI) are diverse compositions, and they also play different roles in blood glucose control. However, no significant influence on $\mathrm{HbAlc}$ was found, when $\mathrm{NA} \times \mathrm{SI}$ term is entered into regression model. These results are consistent with the relationship of Type $\mathrm{D}$ personality and coronary heart disease studies [48]. Interestingly, when NA and SI are entered into regression model as continuous variables, effects of NA and $\mathrm{NA} \times \mathrm{SI}$ term on $\mathrm{HbAlc}$ level were more significantly. Namely, different analysis methods, where Type D personality was regarded as a categorical or a continuous variable, would produce different results, although the underlying mechanism is still unclear. It further showed that how to deal with the variable of Type $\mathrm{D}$ personality deserves further discussion. Relevant studies on this issues should be further conducted in the future in order to explore the underlying mechanism.

Nevertheless, the findings of this study provided new information on the relationship between Type $\mathrm{D}$ personality and HbAlc level in patients with T2DM. Being similar with previous study [27], this study also provided the important preliminary evidence regarding the mediating role of medication adherence between Type D personality and HbAlc level. Therefore, the issue regarding personality patterns in patients with diabetes mellitus should be paid high attention; particularly, the medication adherence of patients with Type $\mathrm{D}$ personality should be intervened in the clinical management of patients with T2DM.

\section{Conclusions}

To the best of our knowledge, this may be the first followup study to explore that Type D personality not only had a direct but also had an indirect influence on HbAlc level through medication adherence. Medication adherence acts as a mediator variable between Type $\mathrm{D}$ personality and $\mathrm{HbAlc}$ level. More importantly, these findings contribute to a growing body of literature exploring the association between Type D personality and HbAlc level when Type D personality is considered as a continuous variable.

\section{Abbreviations}

T2DM: Type 2 diabetes mellitus

FPG: $\quad$ Fasting plasma glucose

RPG: Random plasma glucose

OGTT: Oral glucose tolerance test

HbAlc: Glycated haemoglobin

OLS: Ordinary Least Square Regression

RIF: Recentered Influence Function Regression

BMI: Body mass index

WHO: World Health Organization

IDF: International Diabetes Federation

\begin{abstract}
ADA: American Diabetes Association
NA: Negative affectivity

SI: $\quad$ Social inhibition

MMAS-8-CN: Chinese version of the Medication Adherence Scale.
\end{abstract}

\section{Additional Points}

Limitations. There are some limitations of this study which should be acknowledged. First, this study was limited due to the small sample size and we only adjusted some potential confounders, which might have an impact on HbAlc level in the multiple regression models. Other potential confounders might be ignored. In future studies, larger sample should be included to analyze the influence mechanism between Type D personality and HbAlc. Second, this study did not put early diabetes record variables into the regression model; therefore it may result in some bias. Future studies should consider patient's condition in the past and improve the survey design. Third, the correlational study design precluded casual inferences, and intervention studies were required to establish whether modifying medication adherence can help in controlling HbAlc.

\section{Competing Interests}

The authors declare that they have no competing interests.

\section{Authors' Contributions}

Xuemei Li, Donghua Tian, and Weijun Zhang were involved in the design of this study, research instrument development, and data collection. Shengfa Zhang, Huiwen Xu, Huixuan Zhou, Xiaohua Wang, Jing Guo, and Zhiyong Qu performed the experiments; Min Gao and Weijun Zhang were involved in the data analysis and wrote the manuscript. All authors read and approved the final manuscript. Xuemei Li and Min Gao contributed equally to this work.

\section{Acknowledgments}

The authors thank Beijing Normal University for giving financial support (the Fundamental Research Funds for the Central Universities) to their research. The authors are also grateful to the hospital officials and data collectors for providing support for this study and to all the respondents for participating in this study.

\section{References}

[1] P. V. Burkhart and E. Sabaté, "Adherence to long-term therapies: evidence for action," Journal of Nursing Scholarship, vol. 35, no. 3, p. 207, 2003.

[2] A. Liebl, A. Neiß, A. Spannheimer, U. Reitberger, T. Wagner, and A. Görtz, "Kosten des typ-2-diabetes in deutschland," Deutsche Medizinische Wochenschrift, vol. 126, no. 20, pp. 585-589, 2001.

[3] L. Osterberg and T. Blaschke, "Adherence to medication," The New England Journal of Medicine, vol. 353, no. 5, pp. 487-497, 2005. 
[4] L. Williams, R. C. O'Connor, N. Grubb, and R. O'Carroll, "Type D personality predicts poor medication adherence in myocardial infarction patients," Psychology \& Health, vol. 26, no. 6, pp. 703-712, 2011.

[5] G. J. Molloy, G. Randall, A. Wikman, L. Perkins-Porras, N. Messerli-Bürgy, and A. Steptoe, "Type D personality, selfefficacy, and medication adherence following an acute coronary syndrome," Psychosomatic Medicine, vol. 74, no. 1, pp. 100-106, 2012.

[6] L. Williams, R. C. O'Connor, S. Howard et al., “Type-D personality mechanisms of effect: the role of health-related behavior and social support," Journal of Psychosomatic Research, vol. 64, no. 1, pp. 63-69, 2008.

[7] M. O. M. van de Ven, C. L. M. Witteman, and D. Tiggelman, "Effect of Type D personality on medication adherence in early adolescents with asthma," Journal of Psychosomatic Research, vol. 75, no. 6, pp. 572-576, 2013.

[8] D. B. Pereira, M. H. Antoni, A. Danielson, T. Simon, J. EfantisPotter, and M. J. O'Sullivan, "Inhibited interpersonal coping style predicts poorer adherence to scheduled clinic visits in human immunodeficiency virus infected women at risk for cervical cancer," Annals of Behavioral Medicine, vol. 28, no. 3, pp. 195-202, 2004.

[9] S. M. Curkendall, N. Thomas, K. F. Bell, P. L. Juneau, and A. J. Weiss, "Predictors of medication adherence in patients with type 2 diabetes mellitus," Current Medical Research \& Opinion, vol. 29, no. 10, pp. 1275-1286, 2013.

[10] A. A. Schiffer, O. R. F. Smith, S. S. Pedersen, J. W. Widdershoven, and J. Denollet, "Type D personality and cardiac mortality in patients with chronic heart failure," International Journal of Cardiology, vol. 142, no. 3, pp. 230-235, 2010.

[11] A. E. Aquarius, K. G. Smolderen, J. F. Hamming, J. De Vries, P. W. Vriens, and J. Denollet, "Type D personality and mortality in peripheral arterial disease: a pilot study," Archives of Surgery, vol. 144, no. 8, pp. 728-733, 2009.

[12] Diabetes Complications, http://www.diabetes.co.uk/diabetescomplications/diabetes-complications.html.

[13] Guide to HbAlc, http://www.diabetes.co.uk/what-is-hbalc.html.

[14] M. C. d'Emden, J. E. Shaw, P. G. Colman et al., "The role of HbAlc in the diagnosis of diabetes mellitus in Australia," The Medical Journal of Australia, vol. 197, no. 4, pp. 220-221, 2012.

[15] World Health Organization, Use of Glycated Haemoglobin (HbAlc) in the Diagnosis of Diabetes Mellitus, World Health Organization, Geneva, Switzerland, 2011.

[16] American Diabetes A, "Standards of medical care in diabetes2011," Diabetes Care, vol. 34, supplement 1, pp. S11-S61, 2011.

[17] The Diabetes Control and Complications Trial Research Group, "Hypoglycemia in the diabetes control and complications trial," Diabetes, vol. 46, no. 2, pp. 271-286, 1997.

[18] UKPDS, "Intensive blood-glucose control with sulphonylureas or insulin compared with conventional treatment and risk of complications in patients with type 2 diabetes (UKPDS 33)," Lancet, vol. 352, no. 9131, pp. 837-853, 1998.

[19] X. Li, S. Zhang, H. Xu et al., “Type D personality predicts poor medication adherence in Chinese patients with type 2 diabetes mellitus: a six-month follow-up study," PLoS ONE, vol. 11, no. 2, Article ID e0146892, 2016.

[20] F. E. P. Van Dooren, F. R. J. Verhey, F. Pouwer et al., "Association of Type D personality with increased vulnerability to depression: Is there a role for inflammation or endothelial dysfunction?-The Maastricht Study," Journal of Affective Disorders, vol. 189, article no. 7711, pp. 118-125, 2016.
[21] W. Zhang, H. Xu, S. Zhao et al., "Prevalence and influencing factors of co-morbid depression in patients with type 2 diabetes mellitus: a General Hospital based study," Diabetology \& Metabolic Syndrome, vol. 7, no. 1, article 60, 2015.

[22] W. Zhang, H. Xu, S. Zhao et al., "Prevalence and influencing factors of co-morbid depression in patients with type 2 diabetes mellitus: a general hospital based study," Diabetology and Metabolic Syndrome, vol. 7, no. 1, article no. 60, 2015.

[23] Y. Zhang, H. Li, and S. Zou, "Association between cognitive distortion, type D personality, family environment, and depression in Chinese adolescents," Depression Research and Treatment, vol. 2011, Article ID 143045, 8 pages, 2011.

[24] K.-T. Khaw, N. Wareham, S. Bingham, R. Luben, A. Welch, and N. Day, "Association of hemoglobin Alc with cardiovascular disease and mortality in adults: the European prospective investigation into cancer in Norfolk," Annals of Internal Medicine, vol. 141, no. 6, pp. 413-420, 2004.

[25] W. Jie, M. Yongzhen, and B. Rongwen, "Evaluation of reliability and validity of application of the Chinese version of 8 -item Morisky Medication Adherence Scale in patients with type 2 diabetes," Chinese Journal of Diabetes, vol. 21, pp. 1101-1104, 2013.

[26] S. Firpo, N. Fortin, and T. Lemieux, Decomposing Wage Distributions Using Recentered Influence Function Regressions, University of British Columbia, 2007.

[27] B. J. Murawski, B. I. Chazan, M. C. Balodimos, and J. R. Ryan, "Personality patterns in patients with diabetes mellitus of long duration," Diabetes, vol. 19, no. 4, pp. 259-263, 1970.

[28] S.-J. Sheu, N.-C. Liu, L.-P. Ger et al., "High $\mathrm{HbA}_{1 c}$ level was the most important factor associated with prevalence of diabetic retinopathy in Taiwanese type II diabetic patients with a fixed duration," Graefe's Archive for Clinical and Experimental Ophthalmology, vol. 251, no. 9, pp. 2087-2092, 2013.

[29] S. S. Pedersen and J. Denollet, "Type D personality, cardiac events, and impaired quality of life: a review," European Journal of Cardiovascular Prevention \& Rehabilitation, vol. 10, no. 4, pp. 241-248, 2003.

[30] A. Broström, A. Strömberg, J. Mårtensson, M. Ulander, L. Harder, and E. Svanborg, "Association of Type D personality to perceived side effects and adherence in CPAP-treated patients with OSAS," Journal of Sleep Research, vol. 16, no. 4, pp. 439447, 2007.

[31] M. Dieltjens, O. M. Vanderveken, D. Van den Bosch et al., "Impact of type D personality on adherence to oral appliance therapy for sleep-disordered breathing," Sleep and Breathing, vol. 17, no. 3, pp. 985-991, 2013.

[32] J. Lehtonen and S. Pakarinen, "Right ventricular pacinginduced hypotension," Heart, vol. 93, article 81, 2007.

[33] J. Denollet, "DS14: standard assessment of negative affectivity, social inhibition, and type D personality," Psychosomatic Medicine, vol. 67, no. 1, pp. 89-97, 2005.

[34] J. Denollet, C. J. Vrints, and V. M. Conraads, "Comparing Type D personality and older age as correlates of tumor necrosis factor- $\alpha$ dysregulation in chronic heart failure," Brain, Behavior, and Immunity, vol. 22, no. 5, pp. 736-743, 2008.

[35] G. J. Molloy, L. Perkins-Porras, P. C. Strike, and A. Steptoe, "Type-D personality and cortisol in survivors of acute coronary syndrome," Psychosomatic Medicine, vol. 70, no. 8, pp. 863-868, 2008.

[36] L. Williams, R. E. O'Carroll, and R. C. O'Connor, “Type D personality and cardiac output in response to stress," Psychology \& Health, vol. 24, no. 5, pp. 489-500, 2009. 
[37] P. M. C. Mommersteeg, J. Denollet, and E. J. Martens, “Type D personality, depressive symptoms and work-related health outcomes," Scandinavian Journal of Public Health, vol. 40, no. 1, pp. 35-42, 2012.

[38] A. J. Pelle, A. A. Schiffer, O. R. Smith, J. W. Widdershoven, and J. Denollet, "Inadequate consultation behavior modulates the relationship between Type D personality and impaired health status in chronic heart failure," International Journal of Cardiology, vol. 142, no. 1, pp. 65-71, 2010.

[39] V. M. Conraads, J. Denollet, L. S. De Clerck, W. J. Stevens, C. Bridts, and C. J. Vrints, “Type D personality is associated with increased levels of tumour necrosis factor (TNF)- $\alpha$ and TNF$\alpha$ receptors in chronic heart failure," International Journal of Cardiology, vol. 113, no. 1, pp. 34-38, 2006.

[40] J. Gilmour and L. Williams, “Type D personality is associated with maladaptive health-related behaviours," Journal of Health Psychology, vol. 17, no. 4, pp. 471-478, 2012.

[41] M. Brownlee and I. B. Hirsch, "Glycemic variability: a hemoglobin Alc-independent risk factor for diabetic complications," The Journal of the American Medical Association, vol. 295, no. 14, pp. 1707-1708, 2006.

[42] J. N. de Voogd, J. B. Wempe, K. Postema et al., "More evidence that depressive symptoms predict mortality in COPD patients: is type D personality an alternative explanation?" Annals of Behavioral Medicine, vol. 38, no. 2, pp. 86-93, 2009.

[43] S. E. Maxwell and H. D. Delaney, "Bivariate median splits and spurious statistical significance," Psychological Bulletin, vol. 113, no. 1, pp. 181-190, 1993.

[44] E. Ferguson, L. Williams, R. C. O’Connor et al., "A taxometric analysis of type-D personality," Psychosomatic Medicine, vol. 71, no. 9, pp. 981-986, 2009.

[45] J. Denollet, S. S. Pedersen, C. J. Vrints, and V. M. Conraads, "Predictive value of social inhibition and negative affectivity for cardiovascular events and mortality in patients with coronary artery disease: the type D personality construct," Psychosomatic Medicine, vol. 75, no. 9, pp. 873-881, 2013.

[46] J. Suls and J. Bunde, "Anger, anxiety, and depression as risk factors for cardiovascular disease: the problems and implications of overlapping affective dispositions," Psychological Bulletin, vol. 131, no. 2, pp. 260-300, 2005.

[47] T. W. Smith, "Toward a more systematic, cumulative, and applicable science of personality and health: lessons from type D personality," Psychosomatic Medicine, vol. 73, no. 7, pp. 528532, 2011.

[48] J. Denollet, "Type D personality: a potential risk factor refined," Journal of Psychosomatic Research, vol. 49, no. 4, pp. 255-266, 2000. 


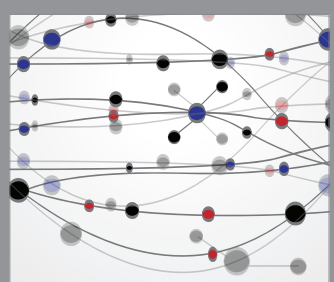

The Scientific World Journal
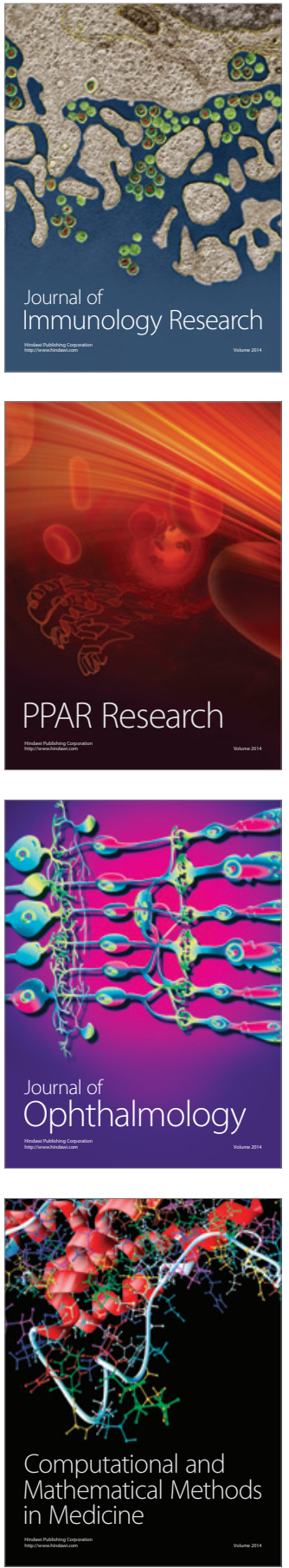

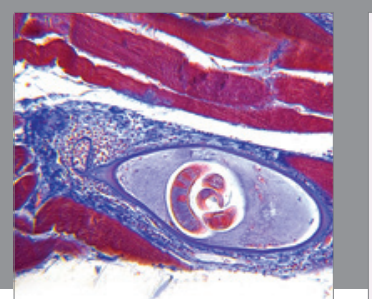

Gastroenterology Research and Practice
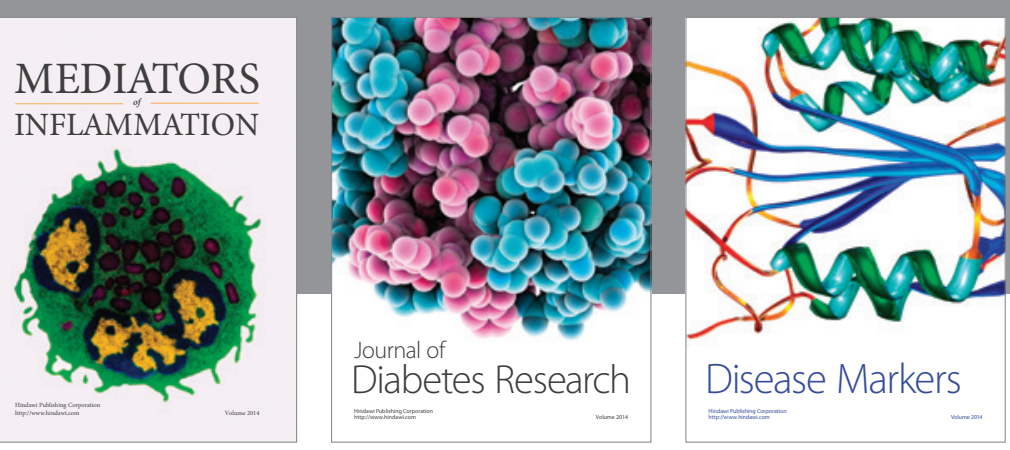

Disease Markers

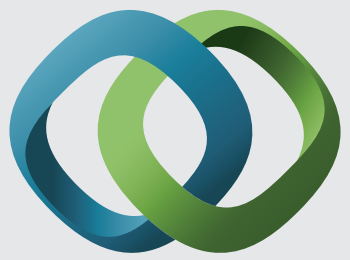

\section{Hindawi}

Submit your manuscripts at

https://www.hindawi.com
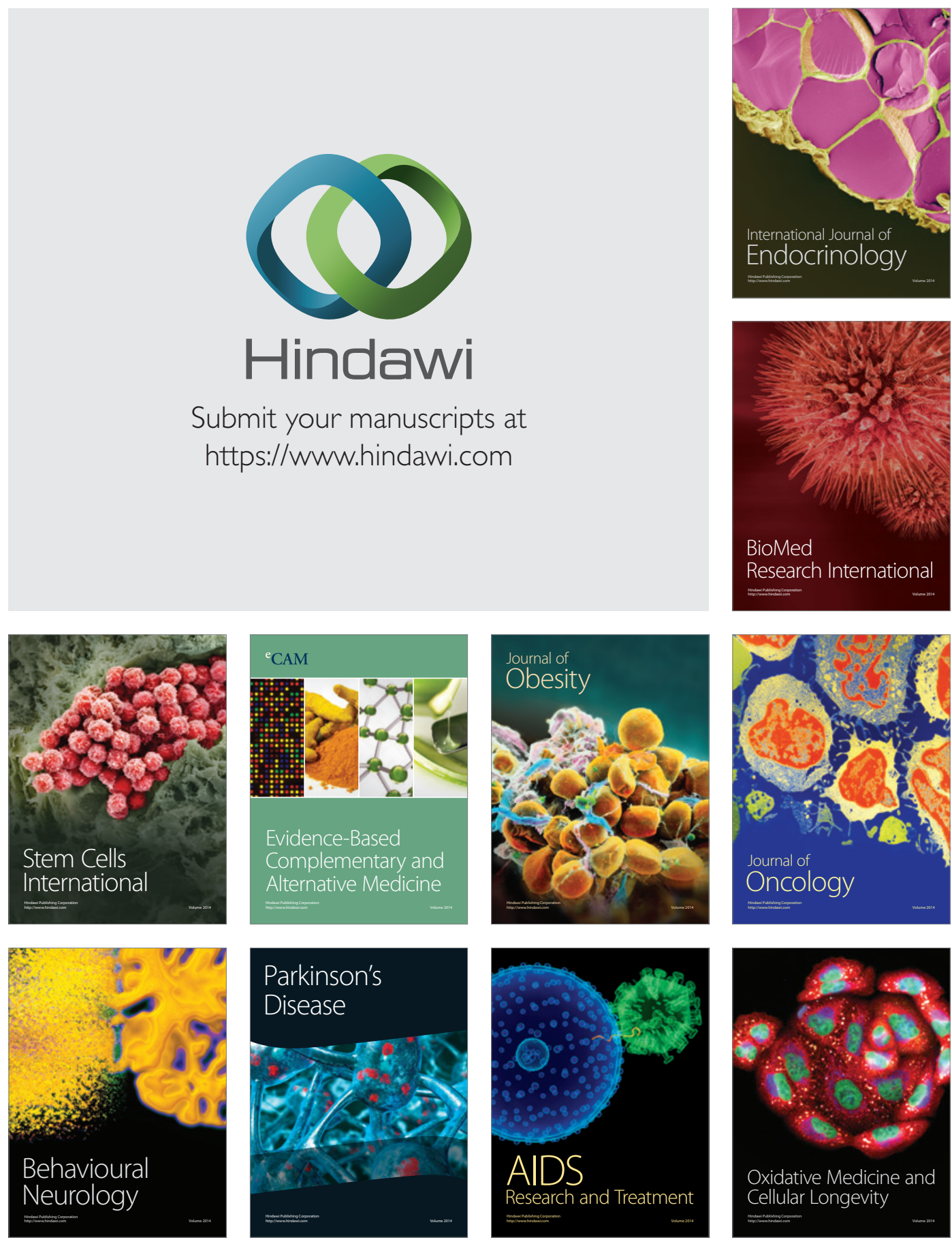